\title{
Maternal malnutrition and anaemia in India: dysregulations leading to the 'thin-fat' phenotype in newborns
}

\author{
Prachi Pandit ${ }^{1}$, Sanjeev Galande ${ }^{1,2,3 *}$ (1) and François Iris ${ }^{1,4}$ \\ ${ }^{1}$ Arbuza Regenerate Private Limited, Pune, India \\ ${ }^{2}$ Department of Biology, Indian Institute of Science Education and Research, Dr. Homi Bhabha Road, Pune 411008, India \\ ${ }^{3}$ Department of Life Sciences, Shiv Nadar University, Delbi-NCR, India \\ ${ }^{4}$ BM-Systems Private Limited, Paris, France
}

(Received 16 February 2021 - Final revision received 5 September 2021 - Accepted 10 September 2021)

Journal of Nutritional Science (2021), vol. 10, e91, page 1 of 15

doi:10.1017/jns.2021.83

Abstract

Maternal and child malnutrition and anaemia remain the leading factors for health loss in India. Low birth weight (LBW) offspring of women suffering from chronic malnutrition and anaemia often exhibit insulin resistance and infantile stunting and wasting, together with increased risk of developing cardiometabolic disorders in adulthood. The resulting self-perpetuating and highly multifactorial disease burden cannot be remedied through uniform dietary recommendations alone. To inform approaches likely to alleviate this disease burden, we implemented a systems-analytical approach that had already proven its efficacy in multiple published studies. We utilised previously published qualitative and quantitative analytical results of rural and urban field studies addressing maternal and infantile metabolic and nutritional parameters to precisely define the range of pathological phenotypes encountered and their individual biological characteristics. These characteristics were then integrated, via extensive literature searches, into metabolic and physiological mechanisms to identify the maternal and foetal metabolic dysregulations most likely to underpin the 'thin-fat' phenotype in LBW infants and its associated pathological consequences. Our analyses reveal hitherto poorly understood maternal nutrition-dependent mechanisms most likely to promote and sustain the self-perpetuating high disease burden, especially in the Indian population. This work suggests that it most probably is the metabolic consequence of 'ill-nutrition' the recent and rapid dietary shifts to high salt, high saturated fats and high sugar but low micronutrient diets - over an adaptation to 'thrifty metabolism' which must be addressed in interventions aiming to significantly alleviate the leading risk factors for health deterioration in India.

Key words: Anaemia: Low birth weight: Malnutrition: Pathological mechanisms: Physiological programming

\section{Introduction}

India is home to almost one-fifth of the world's population. People living in each of its twenty-nine states and seven union territories differ in ethnic origins, cultures, religions and socio-economic means, which are exposed to a wide variety of often difficult climatic and ecological conditions as well as to numerous other factors affecting their health ${ }^{(1,2)}$. A recent survey $^{(3)}$ shows that the overall disease burden per person varies considerably between states, the burden rate due to the major diseases ranging five to ten times amongst states. However, contrarily to the all too often repeated view presenting India as the 'diabetes capital of the world" ${ }^{(4,5)}$, it is maternal and child malnutrition and anaemia which are the leading risk factors for the burden of health problems in India $^{(3)}$. The primary consequences of these are insulin resistance and infantile stunting and wasting; diabetes and obesity

Abbreviations: 5-mTHF, 5-methyltetrahydrofolate; BAT, brown adipocyte tissue; EAA, essential amino acids; FA, fatty acid; GSH, glutathione; Hcy, homocysteine; LBW, low birth weight; PE, phosphatidylethanolamine; SAM, S-adenosyl methionine; TG, triacylglycerol; WAT, white adipocyte tissue

* Corresponding author: Sanjeev Galande, email sanjeev@iiserpune.ac.in

(C) The Author(s), 2021. Published by Cambridge University Press on behalf of The Nutrition Society. This is an Open Access article, distributed under the terms of the Creative Commons Attribution-NonCommercial-NoDerivatives licence (https://creativecommons.org/licenses/by-nc-nd/4.0/), which permits non-commercial re-use, distribution, and reproduction in any medium, provided the original work is unaltered and is properly cited. The written permission of Cambridge University Press must be obtained for commercial re-use or in order to create a derivative work. 
appearing as low prevalence secondary consequences and certainly not as primary causes for the disease burden ${ }^{(3)}$. Dietary behaviours, including foods preferentially consumed, meal frequency and timing, are heavily influenced by the ecology, demography, regions, religions, traditions, seasons, cultural specificities, economic burden and psychosocial beliefs ${ }^{(6)}$. Such beliefs around food choices are extremely deep-rooted and are mostly practised by women especially during pregnancy and lactation ${ }^{(7)}$. These practices determine what they eat, how much, why and when. Consequences of such beliefs are seen in health of women of childbearing age, in newborn babies and in infants and adolescents ${ }^{(8)}$.

Across India, dietary intakes of children and adults in rural and urban areas show gross inadequacy of all nutrients and poor quality of protein ${ }^{(9)}$. Maternal and child malnutrition is characterised by low energy intake (eating less often and small portions) and low dietary diversification. The usual diets are low in proteins, vitamins and micronutrients but rich in carbohydrates and saturated fats. Concurrently, hygiene conditions can vary from very poor to excellent not only between rural areas but within urban centres as well ${ }^{(10)}$. A suboptimal prenatal environment, in particular global nutrient restriction during the periods of placental and embryonic development, is increasingly being recognised as programming physiology, enhancing predisposition for metabolic diseases in adult life ${ }^{(11,12)}$.

Low birth weight (LBW) offspring of women suffering from malnutrition, clinical anaemia and chronic micronutrient shortages, including vitamins, are characterised by elevated subcutaneous adiposity but very low visceral adiposity (thin-fat phenotype $)^{(13,14)}$. They also exhibit insulin resistance and infantile stunting and wasting, together with increased risk of developing cardiometabolic disorders in adulthood, hence promoting a self-perpetuating, highly multifactorial disease burden which cannot be remedied through uniform dietary recommendations $^{(15)}$. To propose coherent modes of interventions likely to alleviate this multifactorial disease burden, it appears necessary to first understand the physiological roots of the pathological phenotypes encountered within affected populations and communities. To this effect, we implemented a previously described $^{(16,17)} \quad$ systems-analytical approach (ComputerAssisted Deductive Integration [CADI]) which had already proven its efficacy in multiple biological contexts ${ }^{(18-21)}$. We utilised the results of previously published field studies ${ }^{(22-27)}$, undertaken in rural as well as urban populations, addressing qualitative phenotypic biomarkers together with the corresponding maternal and infantile metabolic and nutritional parameters (glucose tolerance, circulating levels of individual amino acids, haematocrit, haemoglobin levels, morphological indices and inflammatory parameters) to precisely define the range of pathological phenotypes encountered and their individual biological characteristics. These characteristics were then integrated, via extensive literature searches, into metabolic and physiological mechanisms to identify the dysregulations most likely to underpin the 'thin-fat' phenotype and its associated self-perpetuating high disease burden.

Our studies reveal hitherto poorly understood maternal nutrition-dependent mechanisms most likely to promote and sustain this self-perpetuating situation, suggesting clear avenues for interventions likely to significantly alleviate the leading risk factors for health deterioration in India.

\section{Maternal characteristics in the populations studied}

The data used in this analysis was obtained from Indian population, and all women who participated in the previously published field studies ${ }^{(22-27)}$, whether pregnant or not, were characterised by low body weight, elevated subcutaneous adiposity (thin-fat phenotype), significant anaemia, malnutrition, insulin resistance, low micronutrients and vitamin B12 levels together with low circulating glutathione (GSH), high homocysteine (Hcy), triacylglycerols (TGs) and 5-methyltetrahydrofolate (5-mTHF) levels.

However, in this context, since B12-dependent physiological processes such as odd carbon chain-length fatty acid (FAs) metabolism, serine-glycine interconversion (see later) and nucleic acids synthesis are clearly functional, low vitamin B12 circulating levels, while certainly indicative of vitamin intake deficiency ${ }^{(28)}$, may be representative of high cellular uptake for metabolic purposes rather than low availability ${ }^{(29)}$. Furthermore, it seems highly unlikely that deficiency in vitamin intake could address B12 only. It appears more likely that all essential vitamins would be similarly affected, in particular vitamins $\mathrm{A}, \mathrm{B} 1, \mathrm{~B} 2 \mathrm{~B} 6, \mathrm{~B} 8, \mathrm{~B} 9$ and $\mathrm{C}^{(30)}$. Circulating levels of non-essential and essential amino acids (NEAA and EAA, respectively) were generally low, with the notable exception, most particularly in pregnant women, of aspartic acid which was extremely elevated, followed by elevated serine, threonine and histidine (in descending order, respectively, Table 1).

\section{Integration}

\section{Micronutrient deficits and their effects}

Micronutrients, and in particular zinc and selenium, act as key regulators of metabolic and immune functions ${ }^{(31,32)}$. Zinc deficiency in human subjects is now known to be an important malnutrition problem worldwide. It is more prevalent in areas of high cereal and low animal food consumption not because the diet could be low in zinc and selenium but because phytic acid is the main known inhibitor of zinc absorption ${ }^{(33)}$, while selenocysteine, the organic form of selenium most easily absorbed by human subjects, dominates in products of animal origin $^{(32)}$. Compared to adults, infants, children, adolescents, pregnant and lactating women have increased requirements for zinc and selenium and are at increased risk of deficiencies. Zinc deficiency results in growth failure, while epidermal, gastrointestinal, central nervous, immune, skeletal and reproductive systems are the organs clinically most affected by zinc and selenium deficiencies ${ }^{(34,35)}$.

Hence, in a context characterised by significant maternal malnutrition, micronutrient deficiency during the periconceptional period, and in particular zinc and selenium deficiencies, is likely to result in widespread, low level but persistent maternal as well as foetal metabolic dysregulations with deleterious consequences upon placentation and embryogenesis, 
Table 1. Trends in circulating levels of non-essential and essential amino acids during pregnancy

\begin{tabular}{|c|c|c|c|c|}
\hline Amino acid & Control (n 31) & Pregnant $(\mathrm{V} 1)(n 75)$ & Pregnant (V2)(n 92) & Pregnant $(34 w)(n 30)$ \\
\hline ASPRange $1-4(\mu \mathrm{mol} / \mathrm{l})$ & Elevated (x2-x8) & Elevated (x2-x8) & Elevated $(\mathrm{x} 2-\mathrm{x} 4)$ & Elevated $(x 2-x 4)$ \\
\hline GLURange 10-97 $(\mu \mathrm{mol} / \mathrm{l})$ & Within range & Within low range & Within low range & Within low range \\
\hline ASNRange 31-64 $(\mu \mathrm{mol} / \mathrm{l})$ & Within top range & Within range & Within range & Within range \\
\hline SERRange $65-138(\mu \mathrm{mol} / \mathrm{l})$ & Mainly above range & Within top range & Within top range & Within top range \\
\hline GLNRange 428-747 ( $\mu \mathrm{mol} / \mathrm{l})$ & Within top range & Low to below range & Low to below range & Within range \\
\hline GLYRange $122-322(\mu \mathrm{mol} / \mathrm{l})$ & Within top range & Within top range & Within range & Within range \\
\hline THR ${ }^{\mathrm{a}}$ Range $67-198(\mu \mathrm{mol} / \mathrm{l})$ & Within top range & Within range & Within top range & Within top range \\
\hline CITRange $16-51(\mu \mathrm{mol} / \mathrm{l})$ & Within top range & Within range & Within range & Within range \\
\hline HIST Range 60-109 $(\mu \mathrm{mol} / \mathrm{l})$ & Within top range & Within top range & Within top range & Within top range \\
\hline ALARange $200-483(\mu \mathrm{mol} / \mathrm{l})$ & Within top range & Within low range & Within low range & Within range \\
\hline TAURange 31-102 $(\mu \mathrm{mol} / \mathrm{l})$ & Manly low range & Mainly below range & Below range & Below range \\
\hline TYRRange 38-96 ( $\mu \mathrm{mol} / \mathrm{l})$ & Within range & Low to below range & Within low range & Low to below range \\
\hline ARGRange $43-407(\mu \mathrm{mol} / \mathrm{l})$ & Within range & Within range & Within range & Within range \\
\hline ABARange 7-32 $(\mu \mathrm{mol} / \mathrm{l})$ & Within range & Within range & Within low range & Within low range \\
\hline METH ${ }^{\mathrm{a}}$ Range $16-34(\mu \mathrm{mol} / \mathrm{l})$ & Within low range & Low to below range & Low to below range & Low to below range \\
\hline VAL ${ }^{a}$ Range $132-313(\mu \mathrm{mol} / \mathrm{l})$ & Within range & Low to below range & Mainly below range & Low to below range \\
\hline TRP Range 40-91 $(\mu \mathrm{mol} / \mathrm{l})$ & Mainly below range & Mainly below range & Mainly below range & Below range \\
\hline $\mathrm{PHE}^{\mathrm{a}}$ Range $40-74(\mu \mathrm{mol} / \mathrm{l})$ & Within range & Within low range & Within low range & Low to below range \\
\hline ISO Range 34-98 ( $\mu \mathrm{mol} / \mathrm{l})$ & Within range & Within low range & Within low range & Within low range \\
\hline LEU ${ }^{a}$ Range $73-182(\mu \mathrm{mol} / \mathrm{l})$ & Within range & Mainly within low range & Low to below range & Within low range \\
\hline ORNRange 27-83 ( $\mu \mathrm{mol} / \mathrm{l})$ & Within top range & Mainly within low range & Mainly within low range & Mainly within low range \\
\hline LYS $^{a}$ Range $119-233(\mu \mathrm{mol} / \mathrm{l})$ & Within range & Mainly within low range & Mainly below range & Mainly below range \\
\hline
\end{tabular}

CIT, citrulline; TAU, taurine; ABA, $\alpha$-aminobutyric acid; ORN, ornithine.

The data presented were collected during previously published field studies ${ }^{(22-27)}$. V1 = enrolled at 1 st trimester $(n 75)$; V2=2nd trimester +30 newly enrolled during their 2 nd trimester of pregnancy $(n 72+30)$; 34w $=34$ th week of pregnancy $(n 30$ remaining out of 92$)$.

${ }^{a}$ Essential amino acids.

negatively affecting foetal development as a whole ${ }^{(36)}$. Indeed, an adequate supply of these trace elements is essential for healthy foetoplacental development. For instance, zinc plays major functional roles in zinc-dependent enzymes, zincbinding factors and zinc transporters required in a variety of complex mechanisms during cell replication, maturation and adhesion, such as DNA and RNA metabolism, signal recognition and transduction, gene expression and hormone regulation $^{(37)}$. Among the proteins encoded in the human genome which require zinc for their physiological function are 397 hydrolases, followed by 302 ligases, 167 transferases, 43 oxidoreductases and 24 lyases/isomerases. Proteinases include carboxypeptidases, aminopeptidases, matrix metalloproteinases and peptide hormone processing enzymes/convertases, indicating a wide role of zinc in proteostasis. Hydrolases also include zinc-dependent phosphodiesterases, phospholipases, alkaline and acid phosphatases and pyrophosphatases with roles in regulating second messenger metabolism and signal transduction pathways. Zinc is used in DNA and protein (histone) modification in demethylases and deacetylases, in DNA and RNA metabolism and in DNA repair enzymes. Another significant group of zinc enzymes is involved in regulation: transferases such as geranyl and farnesyl transferase, palmitoyl transferases, ligases such as E3 ubiquitin-protein ligases, SUMO conjugating enzymes and the corresponding hydrolases ${ }^{(38,39)}$.

In parallel, selenium is vital for efficient antioxidant defence in both mother and foetus. Weak placental antioxidant defence due to low maternal plasma selenium concentration increases the risk of small for gestational age infants ${ }^{(40)}$. Many of the beneficial effects of selenium are attributable to its presence as selenocysteine in the selenoproteins, a small but vital group of proteins ${ }^{(41,42)}$. Selenoproteins $\mathrm{W}$ and $\mathrm{N}$ (SELENOW and SELENON) are both required for muscle growth, differentiation and regeneration, as well as satellite cell maintenance in skeletal muscle ${ }^{(43-46)}$. Selenoprotein $\mathrm{S}$ (SELENOS) is involved in the degradation process of misfolded endoplasmic reticulum (ER) luminal proteins ${ }^{(47)}$, while selenoprotein $\mathrm{T}$ (SELENOT) is involved in the control of glucose tolerance by contributing to prolonged adenylate cyclase-activating polypeptide 1 (ADCYAP1/ PACAP)-induced insulin secretion ${ }^{(48)}$ while also contributing to increased quantitative insulin sensitivity ${ }^{(49)}$. Growth retardation, poor appetite and mental lethargy are some of the manifestations of chronically zinc-deficient human subjects ${ }^{(50)}$. Furthermore, low serum zinc has been reported as a major predictor of anaemia mediating the effects of low selenium upon oxidative stress-dependent haemoglobin denaturation and erythrocytes osmotic fragility ${ }^{(51)}$, whereas vitamin B12 and folate deficiencies were found not to be associated with anaemia ${ }^{(52)}$. Table 2 lists the selected key enzymes that are either zinc-/selenium-dependent or the activities of which are controlled by zinc/selenium and are of prime relevance in the context of maternal malnutrition.

Growth retardation, poor appetite and mental lethargy are some of the manifestations of chronically zinc-deficient human subjects ${ }^{(50)}$. Furthermore, low serum zinc has been reported as a major predictor of anaemia mediating the effects of low selenium upon oxidative stress-dependent haemoglobin denaturation and erythrocytes osmotic fragility ${ }^{(51)}$, whereas vitamin B12 and folate deficiencies were found not to be associated with anaemia ${ }^{(52)}$. The foods with the highest zinc contents include meat, shellfish, eggs, nuts and seeds such as hemp, flax, pumpkin or squash. Legumes, such as chickpeas, 
Table 2. List of the key enzymes that are either zinc-/selenium-dependent or the activities of which are controlled by zinc/selenium and are of prime relevance in the context of maternal malnutrition

Physiological roles

References

Zn-dependent enzymes

Aminolevulinic acid dehydrase (ALAD)

Methionine synthase (MTR, also B12-dependent) and homocysteine S-methyltransferase (BHMT) Glyoxalase I (GLOI)

Placental alkaline phosphatase (ALPP) Protein tyrosine phosphatase 1B (PTP1B)

Superoxide dismutase (SOD1)

Leucyl and cystinyl aminopeptidase (LNPEP)

Se-dependent enzymes

Glutathione peroxidases (GPX) 1-4

Thioredoxin reductases (TXNRD) 1/2

Thyroxine deiodinase type I(DIO1)

Thyroxine deiodinase type II (DIO2)

Thyroxine deiodinase type III (DIO3)
Catalyses the second step in the synthesis of the haem portion of haemoglobin, thus playing a key role in haematopoiesis.

Both MTR and BHMT play key roles in the transmethylation-tetrahydrofolate cycle (THF), the attenuation of which leads to Hcy and 5-mTHF accumulation.

Involved in metabolic detoxification, is active in erythrocytes, and requires GSH as a cofactor.

Plays key roles in placental development and nutrients transfer.

Inhibited by Zn, PTP1B dephosphorylates insulin receptor and insulin receptor substrates 1 and 2, thereby inhibiting insulin signalling \& promoting insulin resistance

Cytoplasmic enzymes; converts naturally occurring superoxide radicals to molecular oxygen and hydrogen peroxide. $\mathrm{Zn}$ binding promotes dimerisation and stabilises the native form.

In response to insulin redistributes with GLUT4 to the cell surface in fat and muscle tissues. Cleaves peptide hormones (vasopressin, oxytocin, lys-bradykinin, met-enkephalin and dynorphin A)

Play key limiting roles in $\mathrm{H}_{2} \mathrm{O}_{2}$ accumulation and are negatively associated with heart diseases.

The major $\mathrm{H}_{2} \mathrm{O}_{2}$ scavenger providing a primary defence against $\mathrm{ROS}$ produced by the mitochondrial respiratory chain, regulate mitochondrial integrity.

Catalyse, in the liver, the conversion of the prohormone thyroxine (T4) to the bioactive thyroid hormone (T3) by outer ring 5'-de-iodination and is negatively associated with growth retardation. Expression is $\mathrm{Zn}$-dependent

Catalyse in situ conversion of thyroxine (T4) to the bioactive hormone (T3) in central nervous system (CNS), brown adipose tissue \& muscle, the metabolic functions of which depend on $\mathrm{T} 3$.

Highly expressed in placenta, regulates circulating foetal thyroid hormone concentrations throughout gestation. Essential for the regulation of thyroid hormone inactivation during development

In selenium deficiency, there is a strict hierarchy of selenium supply to specific tissues and also to different selenoenzymes within a tissue. Concentrations of selenium and selenoenzymes are greatly decreased in liver, kidney and muscle, whereas those in the brain and endocrine organs such as the thyroid gland are less affected. Within different organs, specific selenoproteins are retained at the expense of others, presumably to preserve the most important aspects of metabolism in selenium deficiency. For example, in the selenium-deficient rat, DIO1 is better retained than cytoplasmic glutathione peroxidase in thyroid, liver and kidney, presumably in order to preserve thyroid function and iodothyronine de-iodination and to limit changes in plasma T4, T3 and $\mathrm{TSH}^{(76)}$. Many of the beneficial effects of selenium are attributable to its presence as selenocysteine in the selenoproteins, a small but vital group of proteins ${ }^{(41,42)}$. Selenoproteins $\mathrm{W}$ and $\mathrm{N}$ (SELENOW and SELENON) are both required for muscle growth, differentiation and regeneration, as well as satellite cell maintenance in skeletal muscle ${ }^{(43-46)}$. Selenoprotein S (SELENOS) is involved in the degradation process of misfolded endoplasmic reticulum luminal proteins ${ }^{(47)}$, while selenoprotein T (SELENOT) is involved in the control of glucose tolerance by contributing to prolonged adenylate cyclase-activating polypeptide 1 (ADCYAP1/ PACAP)-induced insulin secretion ${ }^{(48)}$ while also contributing to increased quantitative insulin sensitivity ${ }^{(49)}$.

lentils and beans, all contain substantial amounts of zinc, while whole grains like wheat, quinoa, rice and oats contain some zinc (USDA Food Composition Databases). The foods with the highest selenium content include Brazil nuts, fish, meat, dairy products, eggs and bananas (USDA Food Composition Databases). However, low-quality and less varied plant-based diets in low-income communities have a high content of phytic acid [myo-inositol hexaphosphate (InsP6)] and associated magnesium, potassium and calcium salts, termed 'phytate', which together constitute potent inhibitors of iron and zinc absorption and bioavailability ${ }^{(79-81)}$.

Hence, the origin of high to severe anaemia in Indian women and children stands to be a direct consequence of malnutrition compounded by low micronutrient intake, and in particular low availability of zinc and selenium resulting in suboptimal haemoglobin synthesis associated with oxidative stress-dependent haemoglobin denaturation and osmotic fragility of erythrocytes (see earlier). Furthermore, maternal micronutrient deficiency in association with chronic malnutrition will most probably provoke significant maternal metabolic skewing.

\section{Maternal metabolic skewing and its consequences}

Transmethylation cycle (one-carbon metabolism) alterations. Maternal dietary methyl donor intake (methionine, folate and choline) and cofactor (zinc and vitamins B2, B6 and B12) play crucial roles in one-carbon metabolism and DNA methylation in the foetus and placenta, impacting foetal growth and lifelong health outcomes $^{(82)}$. However, in a context characterised by significant maternal malnutrition, not only such dietary intakes will be highly restricted, but the deficiencies in cofactors intake apparently promote down-regulation of the THF-transmethylation cycle. The resulting elevation in Hcy and $5 \mathrm{~m}$ THF concurrently with low GSH circulating levels observed in the populations studied probably does not arise from low vitamin B12 availability but from attenuation of zinc-dependent methionine synthase and betainehomocysteine S-methyltransferase enzymatic activity. Here, high Hyc circulating levels lead to GSH depletion through uncoupling of the activities of NOX (NADPH-dependent) from those of XO [S-adenosylhomocysteine (SAH)dependent] and NOS (BH4-dependent), both of which are 
negatively affected by dysregulation of the transmethylation pathway ${ }^{(83)}$. This dysregulation, resulting in S-adenosyl methionine (SAM) deficiency, besides reducing methylation potential, also has an effect upon choline biosynthesis from phosphatidylethanolamine (PE), each step of which requires methyl groups donated by $\mathrm{SAM}^{(84)}$ (Fig. 1). In pregnancy, increased maternal Hcy levels are associated with increased risk of adverse pregnancy outcomes such as intrauterine growth restriction leading to small size for gestational age at birth and $\mathrm{LBW}^{(85)}$. Dietary protein restriction in animals and marginal protein intake in human subjects cause characteristic changes in one-carbon metabolism that are further exacerbated by micronutrient deficiency, negatively impacting the health of the mother, impairing growth and reprogramming metabolism of the foetus, and causing long-term morbidity in the offspring ${ }^{(82,86)}$.

Amino acid metabolism alterations. Four amino acids (aspartic acid, serine, threonine and histidine) show elevated serum levels in malnourished pregnant women, and in particular aspartic acid is extremely elevated (see Table 1). Under protein deficiency, the NEAA aspartate becomes a significant metabolic hub, a major product of the oxidative glutaminolysis pathway and a required substrate for other anabolic pathways, including the synthesis of purines and pyrimidines ${ }^{(87)}$. Besides playing a key role in the urea cycle as well as in pyrimidine synthesis, aspartate carries reducing equivalents in the malate-aspartate shuttle, which utilises the ready interconversion of aspartate and oxaloacetate in order to maintain mitochondrial oxidative phosphorylation (Fig. 2). Hence, extremely elevated serum aspartate levels could be a consequence of high biosynthesis and interconversion rates. Aspartate can be synthesised by the transamination of oxaloacetate using either alanine or glutamine, yielding aspartate and an $\alpha$-keto acid ${ }^{(8-90)}$. Interestingly, in malnourished pregnant women alanine, and even more so glutamine, show low circulating levels, possibly comforting hypothetically increased aspartate de novo synthesis and interconversion levels.

However, such mechanisms would be at the expense of amino acid supply and cannot be sustained indefinitely. Furthermore, glutamate dehydrogenase, which, in this scheme, catalyses the oxidative deamination of glutamate to $\alpha$-ketoglutarate and ammonia, is zinc-dependent and its activity would be down-regulated by zinc deficiency. This could be alleviated by increased FA oxidative catabolism, provided that sufficient L-carnitine is available. Since diets low in meat and dairy products lead to low L-carnitine uptake, this could be compensated by de novo L-carnitine biosynthesis, which takes place mainly in skeletal muscle, kidney and liver, using L-lysine, an EAA, as primary substrate ${ }^{(91)}$ (Fig. 3). In malnourished pregnant women, serum lysine and methionine levels are lower than those of most other EAAs, indicative of active de novo L-carnitine biosynthesis. However, this methylation-dependent mechanism implicates SAM as methyl group donor ${ }^{(92)}$, hence placing further demands on the transmethylation cycle.

In malnourished pregnant women, serum serine levels also are elevated, while glycine levels are not, suggesting down- modulated activity in serine hydroxymethyltransferasemediated interconversion to glycine (synthesis of 5,10-methylene tetrahydrofolate from tetrahydrofolate) for the cytoplasmic synthesis of thymidylate, purines and methionine regeneration ${ }^{(94-96)}$. Furthermore, high circulating levels of serine might also be indicative of down-regulated PE biosynthesis ${ }^{(97)}$ which, together with SAM deficiency, could lead to low phosphatidylcholine synthesis. This may take particular importance in a context where the availability of choline-rich food items such as fish, crustaceans, meat and eggs are highly limited, since, in pregnancy, choline deficiency could worsen placental dysfunctions while promoting foetal slow growth as gestation progresses.

In human subjects, choline and phosphatidylcholine are synthesised de novo via the PE N-methyltransferase (PEMT) pathway ${ }^{(98)}$ but biosynthesis is not enough to meet physiological requirements ${ }^{(99)}$. In the hepatic PEMT pathway, 3-phosphoglycerate (3PG) receives two acyl groups from acyl-CoA forming a phosphatidic acid. It reacts with cytidine triphosphate to form cytidine diphosphate-diacylglycerol. Its hydroxyl group reacts with serine to form phosphatidylserine which decarboxylates to ethanolamine and PE forms. A PEMT enzyme moves three methyl groups from three SAM donors to the ethanolamine group of the PE to form choline in the form of a phosphatidylcholine. Three SAHs are formed as a by-product ${ }^{(99)}$. Most of the physiological requirements for phosphatidylcholine are met by channelling dietary choline through the CDP pathway which utilises adenosine triphosphate (ATP), cytidine triphosphate (CTP) and diacylglycerol to generate phosphatidylcholine (Fig. 4).

In a context dominated by maternal malnutrition, low protein diet will lead to inhibition of mammalian target of rapamycin complex 1 (mTORC1), thereby promoting autophagy as a mechanism maintaining EAA availability for protein synthesis and protective mechanisms (see later) while supplying ketogenic and glucogenic precursors, such as glutamine and alanine, for ATP generating pathways ${ }^{(101-103)}$. These effects would be amplified during pregnancy, triggering the placental mammalian amino acid response pathway and thereby programming the growth capacity of offspring not only in utero but also long after gestational protein restriction ${ }^{(104,105)}$. Elevated plasma threonine, a member of the EAA group, could reflect zinc and/or vitamin B6 deficiencies, since the initial step in threonine catabolism to Kreb's cycle precursors requires vitamin $\mathrm{B} 6$, the activation of which, via pyridoxal kinase, is zinc-dependent ${ }^{(106,107)}$. However, this would also suggest sufficient dietary supply in EAAs which, in the context addressed here, is highly improbable. Hence, it appears more likely that elevated plasma threonine, arising from maternal autophagy, could supply the developing foetus with an immunostimulant which promotes thymus growth while concurrently promoting maternal innate immune defence functions ${ }^{(108)}$. Elevated plasma histidine, another member of the EAA group, might also play significant protective roles benefiting both the mother and the foetus, particularly in a context dominated by chronic anaemia. Histidine is essential in globin synthesis and erythropoiesis and has also been implicated in the enhancement of iron absorption from human 


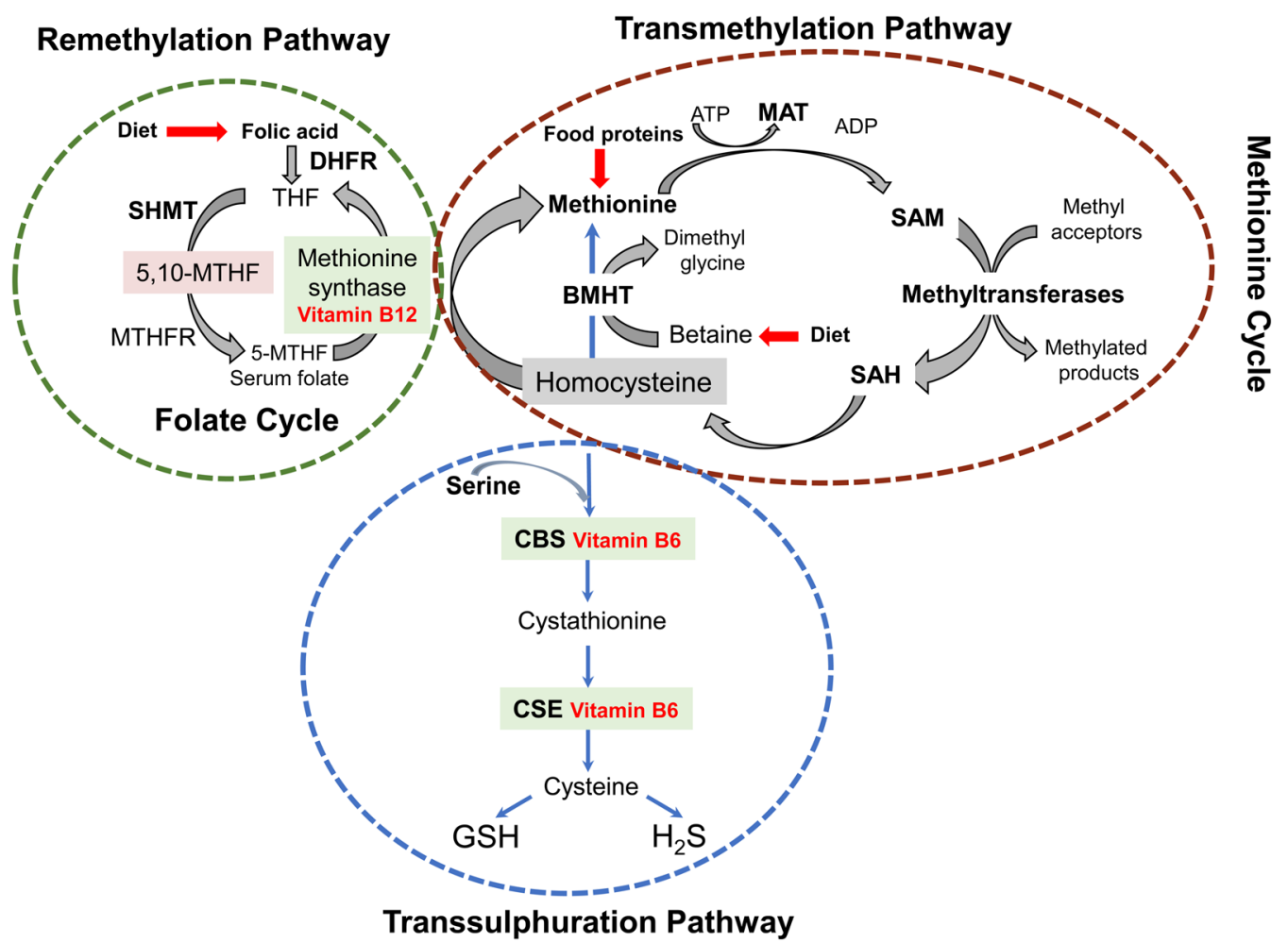

Fig. 1. Schematic representation of the interconnected transmethylation cycle/transsulphuration pathway, a critical branching point in metabolism connecting sulphur metabolism, cofactor chemistries, biological methylations and redox homoeostasis. In these interconnected pathways, methionine synthase (MS) and betaine-homocysteine S-methyltransferase (BHMT) are zinc-dependent enzymes. In parallel, methionine adenosyltransferase (MAT), N-glycine methyltransferase (GNMT), SAH hydrolase, cystathionine $\beta$-synthetase (CBS), $\gamma$-glutamylcysteine synthetase (glutamate-cysteine ligase, GCL), methylenetetrahydrofolate reductase (MTHFR) and serine hydroxymethyltransferase (SHMT) are all regulated by zinc-dependent transcription factors. Additional zinc enzymes are histone and DNA methyltransferases and adenosine deaminase ${ }^{(38,39)}$. DHFR, dihydrofolate reductase; THF, tetrahydrofolate; MTHF, methylenetetrahydrofolate; ATP, adenosine triphosphate; ADP, adenosine diphosphate; SAM, S-adenosyl methionine; SAH, S-adenosylHcy; CSE, cystathionase; GSH, glutathione; H2S, hydrogen sulphide. Figure adapted from Azzini et al. ${ }^{\left({ }^{(5)} \text {. }\right.}$

diets. Histidine-deficient diets predispose healthy subjects to anaemia and accentuate anaemia in chronic uraemic patients ${ }^{(109)}$. Furthermore, histidine plays key roles in the detoxification of cytotoxic oxidative stress metabolites such as reactive carbonyls ${ }^{(110)}$.

FA metabolism alterations. Under conditions characterised by deficit in methyl donors and increased homocysteine levels, $\beta$-oxidation becomes deficient and hypertriglyceridaemia ensues $^{(111)}$ as reflected by high circulating TGs in anaemic Indian women (see earlier). Low amino acid availability, and in particular lysine, may further contribute to high circulating TG levels. Low lysine levels would lead to low L-carnitine de novo synthesis, while diets low in meat and dairy products would lead to low L-carnitine uptake ${ }^{(112)}$. This, in turn, would further impede mitochondrial $\beta$-oxidation of $F A s$ without affecting cytoplasmic FA synthesis from excess carbohydrates intake ${ }^{(113)}$. Under these conditions, mitochondrial $\beta$-oxidation of medium-chain $\mathrm{FA}$, including odd medium-chain FA, the catabolism of which requires the activity of B12-dependent methylmalonyl-CoA mutase, an enzyme indispensable in human metabolism ${ }^{(114)}$, would remain functional. However, both microsomal $\alpha$-oxidation, which requires $\mathrm{Fe}^{2+}$, vitamin $\mathrm{C} / \mathrm{GSH}$ and thiamine (vitamin B1) as cofactors ${ }^{(115,116)}$, as well as $\omega$-oxidation, which requires haem iron protein such as microsomal or mitochondrial cytochrome P-450 $0^{(117)}$ together with zinc-dependent alcohol dehydrogenase, are also likely to be impeded. Hence, peroxisome-mediated $\beta$-oxidation of dietary long- and very long-chain FA and $\alpha$-oxidation of dietary branched-chain FA stand to be favoured. However, this process would also increase oxidative stress since the first step in peroxisome-mediated $\beta$-oxidation results in the generation of $\mathrm{H}_{2} \mathrm{O}_{2}$ and subsequent increase in $\mathrm{Fe}^{2}$ ${ }^{+}$-dependent catalase activity ${ }^{(118)}$. Here, the activity of the main ROS-controlling enzymes (SODs, GLO1, GPXs and TXNRDs) will be attenuated through zinc and selenium deficiencies, while GSH will be subjected to Hcy-mediated depletion. These phenomena stand to exert negative impacts upon placental functions.

Functional placental alterations. During pregnancy, the characteristics of maternal blood biochemistry will necessarily constitute the nutritional supply provided to the developing foetus. Maternal hypertriglyceridaemia during pregnancy is correlated with foetoplacental endothelial dysfunction ${ }^{(119)}$. This can be expected to result in constitutive mild placental (and consequently foetal) hypoxia and subsequent ER stress, which would then affect metabolic control via ATF4 and ATF $6 \beta^{(120)}$. This would stand to further worsen the direct 


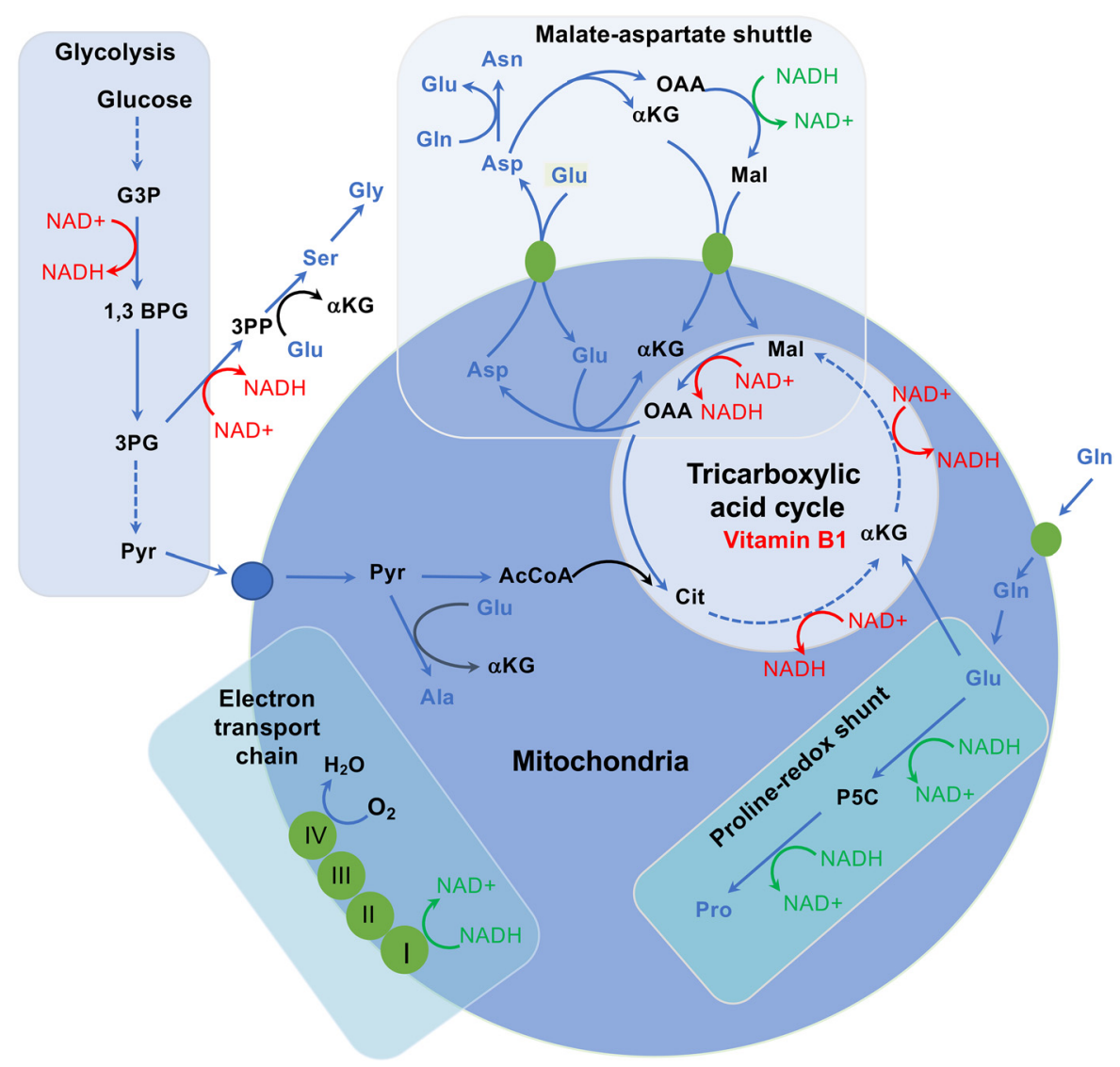

Fig. 2. Interplay between amino acid metabolism and redox homoeostasis. The synthesis and catabolism of amino acids is interwoven into redox homoeostasis. The malate-aspartate shuttle, besides transporting NADH between the cytosol and the mitochondrial matrix, also moves the amino acids glutamate and aspartate between the two compartments and is functionally connected to the TCA cycle. When aspartate is removed from this cycle to synthesise asparagine, arginine or nucleosides, this would disrupt the cycle, requiring additional carbon input. Coupling oxaloacetate (OAA) production in oxidative TCA cycle activity with glutamate production by mitochondrial glutaminase maintains flux of $\alpha$-ketoglutarate into the TCA cycle while removing OAA to permit continued activity, producing reducing potential to generate ATP. In this way, two metabolites central to homoeostasis, ATP and aspartate, are synthesised in parallel. These links go further, given that aspartate, glutamate, $\alpha$-ketoglutarate and malate are functionally coupled through the malate-aspartate shuttle, which is important for moving reducing potential between the matrix and the cytosol. NADH oxidation reactions and NAD+ reduction reactions, which affect the connectivity of this network, are shown in green and red, respectively. Amino acids are represented in blue, while proteins (transporters and electron carriers) are in orange. $\alpha \mathrm{KG}$, $\alpha$-ketoglutarate; $1,3 \mathrm{BPG}$, 1,3-bisphosphoglycerate; 3PG, 3-phosphoglycerate; 3PP, 3-phosphopyruvate; AcCoA, acetyl CoA; Ala, alanine; Asn, asparagine; Asp, aspartate; Cit, citrate; G3P, glyceraldehyde 3-phosphate; Gln, glutamine; Glu, glutamate; Gly, glycine; Lac, lactate; Mal, malate; NAD+, nicotinamide adenine dinucleotide; NADH, reduced NAD+; OAA, oxaloacetate; P5C, pyrroline 5-carboxylate; Pro, proline; Pyr, pyruvate; Ser, serine. Figure adapted from Vettore et al. ${ }^{(87) .}$

effects of maternal anaemia. Additionally, most of the serological maternal characteristics will also be transferred to the foetus via the foetoplacental endothelial system. Hence, in a context dominated by maternal malnutrition, the developing foetus will be constitutively supplied with low vitamins, micronutrients, unbalanced amino acid supply, high TGs and Hcy. Furthermore, due to maternal selenium deficiency, the foetus will also experience a drastically reduced supply of thyroid hormones and in particular low bioactive T3 supply. Furthermore, maternal deficiencies in protein intake will trigger the placental mammalian amino acid response pathway, thereby programming the growth capacity of offspring not only in utero but also long after gestational protein restriction ${ }^{(104,105)}$.

\section{Foetal developmental dysregulations leading to the LBW 'thin-fat' phenotype}

The cord blood of LBW infants is characterised by low adiponectin levels which correlate with hyperinsulinaemia and differential distribution of fat depots giving rise to the newborn's thin-fat phenotype characterised by insulin resistance and increased subcutaneous fat but decreased intra-abdominal fat. Given the marked differences in metabolic and pathophysiological characteristics which differentiate subcutaneous and visceral fat depots ${ }^{(121,122)}$, this situation is radically different from that observed in normal-weight obese individuals of Asian and Indian descent ${ }^{(123,124)}$, characterised by high visceral adiposity and disproportionately lower subcutaneous adiposity $^{(124,125)}$. The fat overflow hypothesis invoked to explain this phenotype $^{(126)}$ does not correlate with the anatomical and pathological consequences observed in association with the 'thin-fat' phenotype of these LBW infants studied here.

Indeed, the lipid overflow/ectopic fat model states that excess visceral fat accumulation, while causally related to the features of insulin resistance, might also be a marker of a dysfunctional adipose tissue being unable to appropriately store the excess calories. According to this model, the body's ability to cope with the surplus of energy (resulting from excess caloric consumption, a sedentary lifestyle or a combination of 
<smiles>CN(C)CCCCC(N)C(=O)O</smiles>

6-N-trimethyllysine (TML)<smiles>CN(C)CCCC(O)C(N)C(=O)O</smiles>

3-hydroxy-6- $\mathrm{N}$-trimethyllysine (HTML)<smiles></smiles>

4- $N$-trimethylaminobutyraldehyde (TMABA)<smiles>C[N+](C)(C)CCCC(=O)O</smiles>

4-N-trimethylaminobutyrate (butyrobetaine, $\mathrm{p}$-BB)<smiles>C[N+](C)(C)CC(O)CC(=O)O</smiles>

L-carnitine

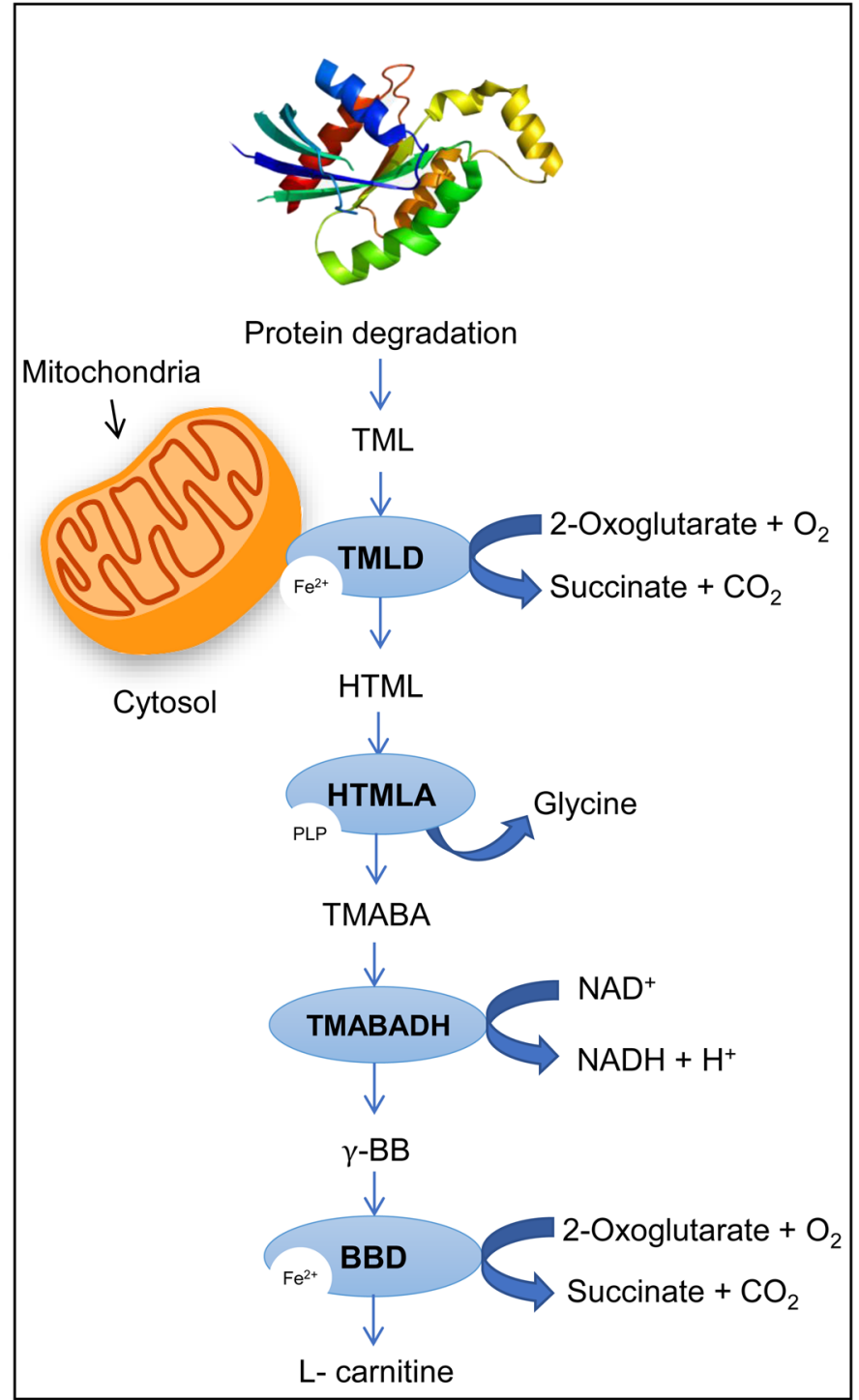

Fig. 3. De novo L-carnitine biosynthesis. (A) Carnitine is synthesised from the amino acids' lysine and methionine. Lysine provides the carbon backbone of carnitine, and the 4-N-methyl groups originate from methionine via the transmethylation pathway (see earlier). (B) In mammals, certain proteins such as calmodulin, myosin, actin, cytochrome $\mathrm{c}$ and histones contain N'-trimethyl-lysine (TML) residues. $\mathrm{N}$-methylation of these lysine residues occurs as a post-translational event. This reaction is catalysed by specific methyltransferases, which use S-adenosyl methionine as a methyl donor. Lysosomal hydrolysis of these proteins results in the release of TML, which is the first metabolite of carnitine biosynthesis. TML is first hydroxylated on the three-position by TML dioxygenase (TMLD) to yield 3-hydroxy TML (HTML). Aldolytic cleavage of HTML yields 4-trimethylaminobutyraldehyde (TMABA) and glycine, a reaction catalysed by HTML aldolase (HTMLA). Dehydrogenation of TMABA by TMABA dehydrogenase (TMABA-DH) results in the formation of 4-Ntrimethylaminobutyrate (butyrobetaine). In the last step, butyrobetaine is hydroxylated on the three-position by $\gamma$-butyrobetaine dioxygenase (BBD) to yield carnitine. Figure adapted from Vaz and Wanders ${ }^{(93)}$.

both factors) might ultimately lead to metabolic syndrome presentation. There is evidence suggesting that if the extra energy is channelled into insulin-sensitive subcutaneous adipose tissue, the individual, although in positive energy balance, will be protected against the development of metabolic syndrome. However, in cases in which adipose tissue is absent, deficient or insulin-resistant with a limited ability to store the energy excess, the triacylglycerol surplus will be deposited at undesirable sites such as the liver, the heart, the skeletal muscle and in visceral adipose tissue, a phenomenon described as ectopic fat deposition. The resulting metabolic consequences include visceral obesity, insulin resistance, atherogenic dyslipidaemia and a pro-thrombotic, inflammatory profile ${ }^{(127)}$. This clearly cannot be invoked to explain the thin-fat phenotype addressed here, characterised by elevated subcutaneous adiposity but very low visceral adiposity (thin-fat phenotype), exhibiting infantile insulin resistance, stunting and wasting, together with increased risk of developing cardiometabolic disorders in adulthood.

\section{Roles of adipokines in the inception of the LBW 'thin-fat' phenotype}

Adiponectin is an adipocyte-derived plasma protein with insulin-sensitizing and anti-atherosclerotic properties. There is no correlation between cord adiponectin levels and maternal body mass index, cord leptin or insulin levels, and there is no correlation between cord and maternal adiponectin levels. However, high cord blood adiponectin levels, compared with serum levels in children and adults, positively correlate with 


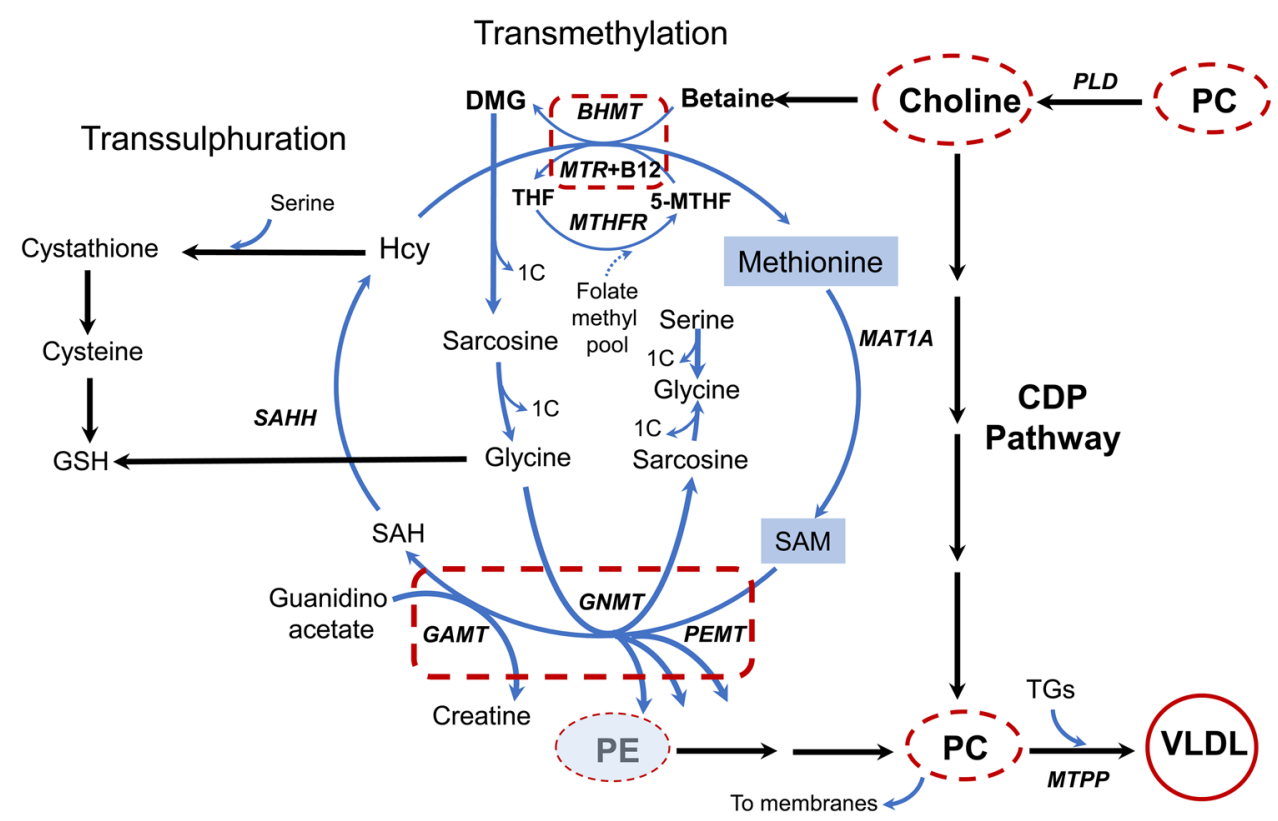

Fig. 4. Intersection between pathways of choline and methionine metabolism in the transmethylation cycle and key enzymes that control methyl group transfer: methionine adenosyltransferase 1A (MAT1A), betaine-homocysteine S-methyltransferase (BHMT), 5-methyltetrahydrofolate-homocysteine methyltransferase (MTR), methylenetetrahydrofolate reductase (MTHFR), microsomal TG transfer protein (MTTP), S-adenosylhomocysteine hydrolase (SAHH), glycine-N-methyltransferase (GNMT), guanidinoacetate N-methyltransferase (GAMT), phosphatidylethanolamine N-methyltransferase (PEMT), vitamin B12 (B12), dimethylglycine (DMG), glutathione (GSH), homocysteine (HCY), S-adenosyl methionine (SAM), S-adenosylhomocysteine (SAH), tetrahydrofolate (THF), phosphatidylethanolamine (PE), phosphatidylcholine (PC), very low-density lipoprotein (VLDL). Figure adapted from Chandler and White ${ }^{(100)}$.

foetal birth weights. Taking fat mass-related parameters such as the birth weight/birth length ratio into consideration, plasma adiponectin concentrations exhibit a significant inverse correlation with insulin concentrations. The high adiponectin levels in newborns may be due to lack of negative feedback on adiponectin production resulting from lack of adipocyte hypertrophy, low percentage of body fat or a different distribution of fat depots in the newborns as compared to children and adults ${ }^{(128-131)}$. This indicates that adiponectin in cord blood is derived from foetal and not from placental or maternal tissues.

During pregnancy, leptin and adiponectin seem to act in an autocrine/paracrine fashion on the placenta and adipose tissue, playing a role in the maternal-foetal interface and contributing to glucose metabolism and foetal development ${ }^{(132)}$. Hence, the low cord blood adiponectin levels observed in LBW births and its correlation with hyperinsulinaemia and differential distribution of fat depots giving rise to the newborn's thin-fat phenotype clearly suggest that the metabolic skewing resulting from maternal malnutrition and anaemia induce significant changes in foetal metabolism.

\section{Cumulative effects of maternal malnutrition and placental alterations in the development of the LBW 'thin-fat' phenotype}

Maternal nutrition, particularly micronutrients, vitamins and omega-3 FAs play a role in modulating the activity of peroxisome proliferator-activated receptors (PPARs) during placentation and angiogenesis, which affects placental and foetal growth $^{(133)}$. In placental angiogenesis, PPAR $\gamma$ signalling causes increased vascular endothelial growth factor receptor 2
(VEGFR2) expression. VEGF binding to VEGFR2 then mediates angiogenic signalling involving increases in NOS activity $^{(134,135)}$. Hcy suppresses PPAR $\gamma$ signalling and expression $^{(136)}$ while impeding NO production. Hence, during pregnancy, the multiple methylation network dysregulations resulting from micronutrient and vitamin deficiencies are likely to primarily result in placental vascularisation defects, while endothelial ER-stress resulting from chronically elevated Hcy levels ${ }^{(137)}$ is in turn likely to result in elevated placental leptin production. These factors, together with the low circulating levels of vitamins, micronutrients and amino acids together with high TGs, are now likely to have serious consequences upon foetal development, predisposing the newborn to insulin resistance, dyslipidaemia ${ }^{(138)}$ and preferential subcutaneous adipocyte patterning, whereas imbalance in the availability of amino acids and low T3 hormone production, resulting from selenium deficiency, will promote growth retardation ${ }^{(73)}$.

\section{Differential adipocyte patterning and dyslipidaemia mechanisms in the development of the LBW 'thin-fat' phenotype}

In mammals, individual white and brown adipocyte tissues (WAT and BAT, respectively) depots appear at different times in development and have unique functional characteristics. The distinction between subcutaneous and visceral fat may be oversimplified because evidence suggests that metabolic properties vary between some visceral fat depots, while heterogeneity exists even within a single fat depot ${ }^{(139)}$. Furthermore, metabolic and environmental challenges highlight the extraordinary plasticity of the mammalian adipose organ. Two distinct subtypes of preadipocytes have been characterised in human fat $\left(\mathrm{Myf5}^{+}\right.$and 
$\mathrm{Myf5}^{-}$), the proportions of which vary among depot locations ${ }^{(140,141)}$. Despite the heterogeneity in the adipocyte precursor cell compartment, it appears that the $\mathrm{Myf} 5^{+}$lineage may selectively differentiate in the BAT, subcutaneous and retroperitoneal WAT (sWAT and rWAT, respectively), while Myf5 lineages selectively give rise to most adipocytes in the inguinal and visceral WAT (ingWAT and vWAT, respectively) ${ }^{(142)}$. Up-regulation of the PI3K-Akt-mTORC1 pathway (PTEN silencing) dramatically redistributes body fat such that interscapular WAT (iWAT), sWAT and rWAT (the $\mathrm{Myf5}^{+}$lineage depots) expand, while the ingWAT and vWAT (the Myf5 ${ }^{-}$lineage depots) disappear ${ }^{(142)}$. In other words, the adipocytes of $\mathrm{Myf5}^{+}$lineage expand (causing lipohypertrophy of BAT, sWATs and rWAT) at the expense of $\mathrm{Myf5}^{-}$lineage (i.e. inguinal and visceral WAT).

Hence, the thin-fat phenotype of LBW infants, characterised by increased subcutaneous fat but decreased intra-abdominal fat, is clearly indicative of metabolic skewing towards AKT-mediated mTORC1 up-regulation, probably as a result of elevated Hcy and insulin supply, concurrently with foetal hypoxia and oxidative stress, as a result of placental dysfunction cumulatively with significant maternal anaemia, during in utero development ${ }^{(143)}$. As a direct consequence, adipogenesis (lineage commitment, clonal expansion and terminal differentiation of preadipocytes) and lipogenesis in adipose tissue will be promoted, while $\beta$-oxidation and ketogenesis will be attenuated, leading to dyslipidaemia and insulin resistance $^{(144)}$, a situation which shall remain dominant after birth. Should the affected individual be then exposed to chronic malnutrition, these developmental phenomena will then have predisposing effects towards stunting/wasting and the development of cardiovascular diseases later in life.

\section{Post-birth nutrition and stunting/wasting in 'thin-fat' phenotype individuals}

Following weaning, LBW infants are subjected to the same restrictive dietary conditions experienced by their parents, namely malnutrition characterised by diets low in proteins, vitamins and micronutrients but rich in carbohydrates and saturated fats, leading to metabolic dysfunctions, including significant anaemia, which will be considerably worsened by increased consumption of low-quality processed products rich in saturated fats, salt and sugars and low in vitamins and micronutrients (ill-nutrition, or so-called junk food). In this context, the deficiencies in micronutrients and metabolic cofactors, and in particular selenium and vitamins, appear to play a key role. Recurrent nightly leg muscle cramps, muscle weakness and fatigue, are indicative of significant L-carnitine deficiency $^{(145)}$ and subsequent dysregulation of FA metabolism (see earlier), non-ketotic hypoglycaemia and muscle wasting ${ }^{(146)}$. The latter effect stands to be further reinforced by selenium deficiency. Selenium bioavailability, which, in muscles, plays a key role in oxidative stress defence and calcium transport control, and the development of nutritional muscular dystrophies affecting cardiac and skeletal muscles have long been established both in human subjects and livestock. Skeletal muscle degeneration leads to muscle weakness or stiffness, postural instability or walking disability, while cardiac muscle degeneration is associated with respiratory distress, cardiogenic shock, enlarged heart, cardiac arrhythmias, congestive heart failure and ultimately sudden death ${ }^{(147)}$. Concurrently, selenium deficiency will also result in deficient thyroid hormone supply ${ }^{(73)}$ which, conjunctly with malnutrition, will promote stunting.

It is important to note that the results of malnutrition, such as deficiencies in amino acids, vitamins and micronutrients together with an oversupply of saturated fats, do not lead to the full inhibition or full activation of metabolic reactions or pathways. These deficiencies and/or oversupplies are not absolute but only relative and act as 'rheostats', slowing down or facilitating particular metabolic reactions or pathways. These will in turn have discrete metabolic skewing effects, the cumulative result of which will swing development in a particular direction while opening the door to predisposing effects towards context-dependent pathologies over longer period.

\section{Conclusion}

According to the earlier analysis, significant maternal malnutrition leads to deficiencies in amino acids, vitamins and micronutrients together with an oversupply of saturated fats. These deficiencies result in alterations affecting key maternal metabolic processes, and in particular the amino acid interconversion, transmethylation, FA oxidation and redox control pathways. These alterations, together with the deficiencies in micronutrients, result in high maternal anaemia, exacerbated during pregnancy and placental dysfunctions. The ensuing alterations in oxygen and nutrients supply to the embryo give rise to in utero foetal metabolic alterations. This results in LBW children characterised by high subcutaneous but low abdominal adipocyte deposits and already existing insulin resistance (Figure 5). Being raised in the same environment as their parents promote significant anaemia, accompanied by stunting and wasting in late childhood, repeating the same cycle as in their parents. Should these individuals shift, during mid to late childhood, to a food environment which primarily consists of processed foods low in proteins, vitamins and micronutrients but rich in saturated fats, salt and sugar (so-called junk food), their condition stands to be worsened by the appearance of significantly increased insulin resistance and the pathogenesis of cardiovascular and metabolic disorders. These individuals, after reaching sexual maturity, are now likely to perpetuate this deleterious cycle via their own children.

However, attempts to remedy this situation must take into consideration the history of Indian diets. This history demonstrates gradual transitions over the centuries from a low energy diet of large quantities of indigestible fibre carbohydrate, small amounts of digestible carbohydrate, moderate fat and moderate protein, to an increasing intake of low fibre and refined carbohydrates associated with increased fat and decreasing intake of animal proteins interspersed with variable periods of starvation. There were fourteen recorded famines in India between the 11 th and 17 th centuries, while those that took place over the course of the 18th, 19th and early 20th centuries 


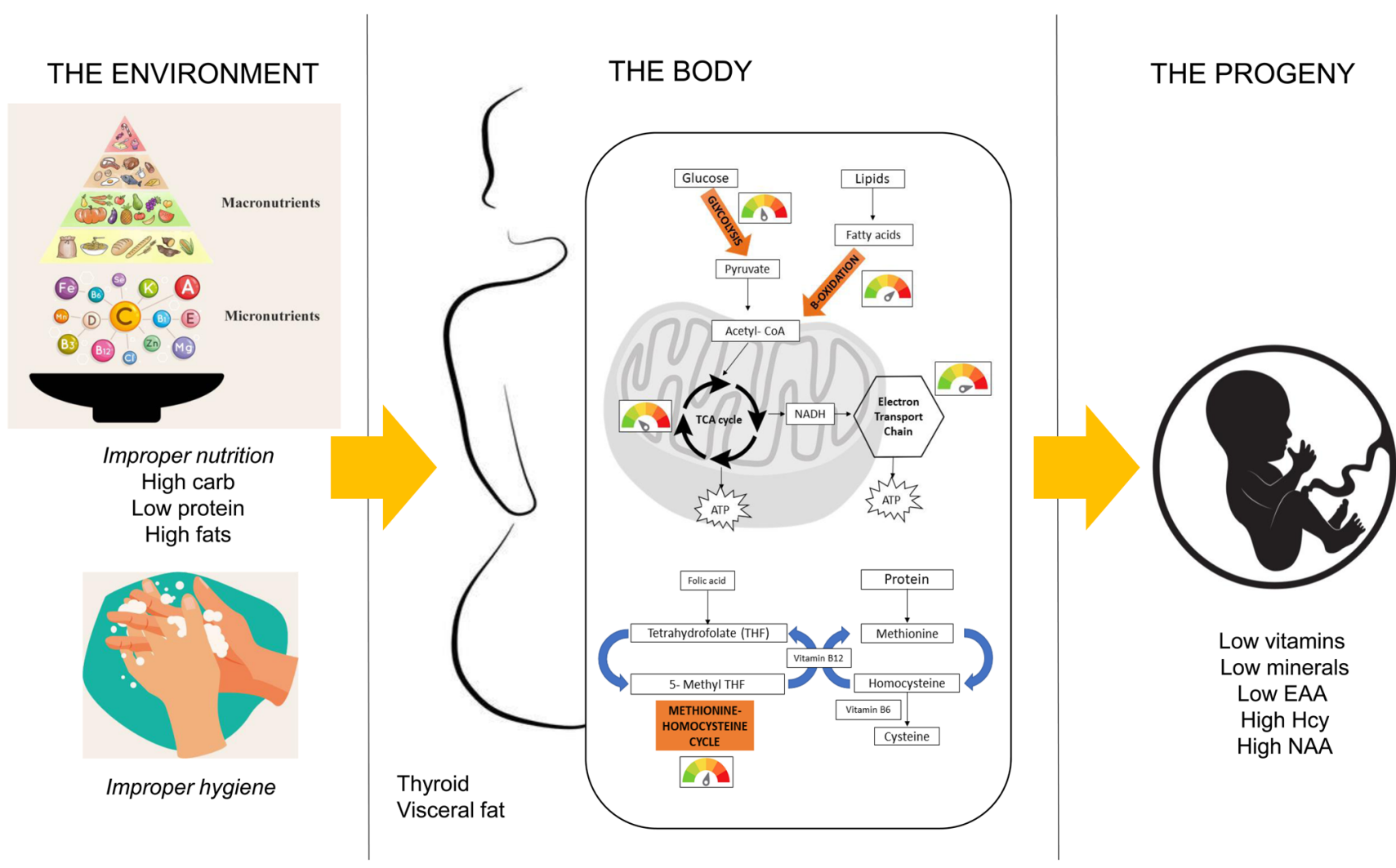

Fig. 5. The mechanisms whereby maternal chronic malnutrition compounded by ill-nutrition leads to the 'thin-fat' phenotype in newborn. Maternal diet chronically low in proteins, micronutrients and carbohydrates but high in fat, compounded by deficient hygiene (left panel) leads to multiple maternal metabolic alterations resulting in high maternal anaemia, exacerbated during pregnancy, together with placental dysfunction (middle panel). Subsequently, these maternal metabolic and placental dysfunctions induce in utero foetal development alterations resulting in low birth weight children, characterised by high subcutaneous but low abdominal adipocyte deposits and already existing insulin resistance ('thin-fat' phenotype, right panel). Being raised in the same environment as their parents promote significant anaemia, accompanied by stunting and wasting in late childhood, repeating the same cycle as in their parents. Should these children then be exposed, during mid-to-late childhood, to a food environment primarily consisting in highly processed products low in vitamins and micronutrients but rich in salt, sugar and fat (ill-nutrition, so-called junk food), their condition stands to be worsened by the appearance of significantly increased insulin resistance and heightened susceptibility to the pathogenesis of cardiovascular (CVD) and metabolic disorders. These individuals, after reaching sexual maturity, are likely to perpetuate this deleterious cycle via their own children.

resulted in more than 60 million deaths ${ }^{(148)}$. Currently, food intake patterns show that most Indians are vegetarians consuming poor and monotonous cereals-based diets and that food items rich in micronutrients (pulses, other vegetables, fruits, nuts, oilseeds and animal foods) are generally consumed less frequently ${ }^{(149)}$. However, from 1947 onwards there has been an increase in the frequency of intake and quantities of low fibre and refined carbohydrates, with protein intake improving only marginally while intakes of industrially processed foods containing high salt, high saturated fats and high sugar but low micronutrients kept increasing ${ }^{(148,150,151)}$. Hence, Indian populations are most probably genetically as well as epigenetically adapted to forms of 'chronic malnutrition' characterised by low energy, low refined carbohydrates, low protein and moderate fat intake with seasonal variation in micronutrient intake (thrifty metabolism). Hence, it most probably is the metabolic consequences of the recent and rapid dietary shifts over an adaptation to 'thrifty metabolism' which must be addressed.

The task is made more challenging by the complexity of political, economic, climatic, social and cultural factors twined together. The resolution of malnutrition-associated problems will require a product well suited to the cultures addressed and developed in light of the actual needs as depicted by the biological evidence. To alleviate the consequences of malnutrition, improvement in affordability, accessibility, delivery to end-users, knowledge and awareness of social and cultural constrains and, most importantly, in the convergence between demand and supply must also be addressed. The solution therefore cannot merely consist in providing a 'one size fits all' supplement but in the use of a well-designed supplement which suits the nutritional requirements along with a social and behaviour change approach, training the beneficiaries in the basics of nutrition based on what is locally available and accessible.

\section{Acknowledgments}

The authors wish to thank Fatema Rajgara and Ayush Madhok for help with formatting and references.

The present study was partly funded by the internal research programmes of BM-Systems Pvt Ltd and Arbuza Regenerate Pvt Ltd. Work in SG laboratory was partly supported by research grant from the Department of Biotechnology (DBT), Government of India (No. CEIB-BT/PR12629/MED/97/ 364/2016). SG is recipient of the JC Bose National Fellowship 
(No. JCB/2019/000013) from the Science and Engineering Research Board, Government of India.

P.P., F.I. and S.G. conceived and coordinated the study. P.P. collected and formatted the data, F.I. performed the systems analyses, and S.G., P.P. and F.I. wrote the MS.

Ethical standards disclosure is not applicable; analysis performed using data from previously published studies.

The authors are founding directors of Arbuza Regenerate Pvt Ltd. F.I. is the Chief Scientific Officer at BM-Systems Pvt Ltd.

\section{References}

1. Bush KF, Luber G, Kotha SR, et al. (2011) Impacts of climate change on public health in India: future research directions. Environ Health Perspect 119, 765-770.

2. Narain JP (2016) Public health challenges in India: seizing the opportunities. Indian J Community Med 41, 85-88.

3. Simon Iain Hay RAS, Ashkan A, Sanjay A, et al. (2017) India: Health of the Nation's States - The India State-Level Disease Burden Initiative. New Delhi, India: Indian Council of Medical Research.

4. Yajnik CS (2002) The lifecycle effects of nutrition and body size on adult adiposity, diabetes and cardiovascular disease. Obes Rev 3, 217-224.

5. Wells JC, Pomeroy E, Walimbe SR, et al. (2016) The elevated susceptibility to diabetes in India: an evolutionary perspective. Front Public Health 4, 145.

6. Green R, Milner J, Joy EJ, et al. (2016) Dietary patterns in India: a systematic review. Br J Nutr 116, 142-148.

7. Sharma S, Akhtar F, Singh R K, et al. (2020) Dietary patterns and determinants of pregnant and lactating women from marginalized communities in India: a community-based cross-sectional study. Front Nutr 7, 595170.

8. Zaveri A, Paul P, Saha J, et al. (2020) Maternal determinants of low birth weight among Indian children: evidence from the National Family Health Survey-4, 2015-16. PLOS ONE 15, e0244562.

9. Hemalatha R, Toteja GS \& Bhargava B (2018) It's time we turn our attention to quality of food as well. Indian J Med Res 148, 469-471.

10. Kumar GS, Kar SS \& Jain A (2011) Health and environmental sanitation in India: issues for prioritizing control strategies. Indian J Occup Environ Med 15, 93-96.

11. Ojha S, Robinson L, Symonds ME, et al. (2013) Suboptimal maternal nutrition affects offspring health in adult life. Early Hum Dev 89, 909-913.

12. Symonds ME, Budge H, Stephenson T, et al. (2005) Leptin, fetal nutrition, and long-term outcomes for adult hypertension. Endothelium 12, 73-79.

13. Yajnik CS, Fall CH, Coyaji KJ, et al. (2003) Neonatal anthropometry: the thin-fat Indian baby. The Pune Maternal Nutrition Study. Int J Obes Relat Metab Disord 27, 173-180.

14. Kurpad AV, Varadharajan KS \& Aeberli I (2011) The thin-fat phenotype and global metabolic disease risk. Curr Opin Clin Nutr Metab Care 14, 542-547.

15. Joy EJ, Green R, Agrawal S, et al. (2017) Dietary patterns and noncommunicable disease risk in Indian adults: secondary analysis of Indian Migration Study data. Public Health Nutr 20, 1963-1972.

16. Iris F, Beopoulos A \& Gea M (2018) How scientific literature analysis yields innovative therapeutic hypothesis through integrative iterations. Curr Opin Pharmacol 42, 62-70.

17. Iris F, Gea M, Lampe PH, et al. (2009) Production and implementation of predictive biological models]. Med Sci 25, 608-616.

18. Gadal F, Starzec A, Bozic C, et al. (2005) Integrative analysis of gene expression patterns predicts specific modulations of defined cell functions by estrogen and tamoxifen in MCF7 breast cancer cells. J Mol Endocrinol 34, 61-75.
19. Pouillot F, Blois H \& Iris F (2010) Genetically engineered virulent phage banks in the detection and control of emergent pathogenic bacteria. Biosecur Bioterror 8, 155-169.

20. Iris F (2012) Psychiatric systems medicine: closer at hand than anticipated but not with the expected portrait. Pharmacopsychiatry 45, S12-S21.

21. Troisi J, Autio R, Beopoulos T, et al. (2020) Genome, environment, microbiome and metabolome in autism (GEMMA) study design: biomarkers identification for precision treatment and primary prevention of autism spectrum disorders by an integrated multi-omics systems biology approach. Brain Sci 10, 743.

22. Katre P, Bhat D, Lubree H, et al. (2010) Vitamin B12 and folic acid supplementation and plasma total homocysteine concentrations in pregnant Indian women with low B12 and high folate status. Asia Pac J Clin Nutr 19, 335-343.

23. Yajnik CS, Chandak GR, Joglekar C, et al. (2014) Maternal homocysteine in pregnancy and offspring birthweight: epidemiological associations and Mendelian randomization analysis. Int $J$ Epidemiol 43, 1487-1497.

24. Deshmukh U, Katre P \& Yajnik CS (2013) Influence of maternal vitamin B12 and folate on growth and insulin resistance in the offspring. Nestle Nutr Inst Workshop Ser 74, 145-154; discussion 154-146.

25. Hardikar PS, Joshi SM, Bhat DS, et al. (2013) Response to comment on: Hardikar et al. Spuriously high prevalence of prediabetes diagnosed by $\mathrm{HbA}(1 \mathrm{c})$ in young Indians partly explained by hematological factors and iron deficiency anemia. Diabetes Care 2012 35;797-802. Diabetes Care 36, e24.

26. Bhat DS, Gruca LL, Bennett CD, et al. (2018) Evaluation of tracer labelled methionine load test in vitamin B-12 deficient adolescent women. PLOS ONE 13, e0196970.

27. Katre P, Joshi S, Bhat DS, et al. (2016) Effect of multi-nutrient insufficiency on markers of one carbon metabolism in young women: response to a methionine load. Eur J Clin Nutr 70, 687-693.

28. Green R (2017) Vitamin B12 deficiency from the perspective of a practicing hematologist. Blood 129, 2603-2611.

29. Hannibal L, Lysne V, Bjorke-Monsen AL, et al. (2016) Biomarkers and algorithms for the diagnosis of vitamin B12 deficiency. Front Mol Biosci 3, 27.

30. Nunn RL, Kehoe SH, Chopra H, et al. (2019) Dietary micronutrient intakes among women of reproductive age in Mumbai slums. Eur J Clin Nutr 73, 1536-1545.

31. Elmadfa I \& Meyer AL (2019) The role of the status of selected micronutrients in shaping the immune function. Endocr Metab Immune Disord Drug Targets 19, 1100-1115.

32. Kieliszek M (2019) Selenium(-)fascinating microelement, properties and sources in food. Molecules 24, 1298.

33. Oberleas D \& Harland BF (1981) Phytate content of foods: effect on dietary zinc bioavailability. J Am Diet Assoc 79, 433-436.

34. Xu Y, Hao Z, Li Y, et al. (2020) Distribution of selenium and zinc in soil-crop system and their relationship with environmental factors. Chemosphere 242, 125289.

35. Roohani N, Hurrell R, Kelishadi R, et al. (2013) Zinc and its importance for human health: an integrative review. $J$ Res Med Sci 18, 144-157.

36. Cetin I, Berti C \& Calabrese S (2010) Role of micronutrients in the periconceptional period. Hum Reprod Update 16, 80-95.

37. Donangelo CM \& King JC (2012) Maternal zinc intakes and homeostatic adjustments during pregnancy and lactation. Nutrients 4, 782-798.

38. Maret W (2019) The redox biology of redox-inert zinc ions. Free Radic Biol Med 134, 311-326.

39. Andreini C, Banci L, Bertini I, et al. (2006) Counting the zincproteins encoded in the human genome. J Proteome Res 5, 196-201.

40. Iqbal S, Ali I, Rust P, et al. (2020) Selenium, zinc, and manganese status in pregnant women and its relation to maternal and child complications. Nutrients 12, 725.

41. Pappas AC, Zoidis E, Surai PF, et al. (2008) Selenoproteins and maternal nutrition. Comp Biochem Physiol B Biochem Mol Biol 151, $361-372$. 
42. Roman M, Jitaru P \& Barbante C (2014) Selenium biochemistry and its role for human health. Metallomics 6, 25-54.

43. Castets P, Bertrand AT, Beuvin M, et al. (2011) Satellite cell loss and impaired muscle regeneration in selenoprotein $\mathrm{N}$ deficiency. Hum Mol Genet 20, 694-704.

44. Arbogast S, Beuvin M, Fraysse B, et al. (2009) Oxidative stress in SEPN1-related myopathy: from pathophysiology to treatment. Ann Neurol 65, 677-686.

45. Jurynec MJ, Xia R, Mackrill JJ, et al. (2008) Selenoprotein N is required for ryanodine receptor calcium release channel activity in human and zebrafish muscle. Proc Natl Acad Sci US A 105, 12485-12490.

46. Brown KM \& Arthur JR (2001) Selenium, selenoproteins and human health: a review. Public Health Nutr 4, 593-599.

47. Williams K \& Dhoot GK (1992) Heterogeneity and distribution of fast myosin heavy chains in some adult vertebrate skeletal muscles. Histochemistry 97, 361-370.

48. Prevost G, Arabo A, Jian L, et al. (2013) The PACAP-regulated gene selenoprotein $\mathrm{T}$ is abundantly expressed in mouse and human beta-cells and its targeted inactivation impairs glucose tolerance. Endocrinology 154, 3796-3806.

49. Tabrizi R, Akbari M, Moosazadeh M, et al. (2017) The effects of selenium supplementation on glucose metabolism and lipid profiles among patients with metabolic diseases: a systematic review and meta-analysis of randomized controlled trials. Horm Metab Res 49, 826-830.

50. Prasad AS (1983) Zinc deficiency in human subjects. Prog Clin Biol Res 129, 1-33.

51. Houghton LA, Parnell WR, Thomson CD, et al. (2016) Serum zinc is a major predictor of anemia and mediates the effect of selenium on hemoglobin in school-aged children in a nationally representative survey in New Zealand. J Nutr 146, 1670-1676.

52. Wirth JP, Woodruff BA, Engle-Stone R, et al. (2017) Predictors of anemia in women of reproductive age: Biomarkers Reflecting Inflammation and Nutritional Determinants of anemia (BRINDA) project. Am J Clin Nutr 106, 416S-427S.

53. Garnica AD (1981) Trace metals and hemoglobin metabolism. Ann Clin Lab Sci 11, 220-228.

54. Reid HW, Plowright W \& Rowe LW (1975) Neutralising antibody to herpesviruses dervied from wildebeest and hartebeest in wild animals in East Africa. Res Vet Sci 18, 269-273.

55. Wai KM, Sawada K, Kumagai M, et al. (2020) Relationship between selected trace elements and hematological parameters among Japanese community dwellers. Nutrients 12, 1615.

56. Chandler AL, Hobbs CA, Mosley BS, et al. (2012) Neural tube defects and maternal intake of micronutrients related to onecarbon metabolism or antioxidant activity. Birth Defects Res $A$ Clin Mol Teratol 94, 864-874.

57. Ashworth CJ \& Antipatis C (2001) Micronutrient programming of development throughout gestation. Reproduction 122, 527-535.

58. Al-Balas QA, Hassan MA, Al-Shar'i NA, et al. (2019) Recent advances in glyoxalase-I inhibition. Mini Rev Med Chem 19, 281291.

59. He Y, Zhou C, Huang M, et al. (2020) Glyoxalase system: a systematic review of its biological activity, related-diseases, screening methods and small molecule regulators. Biomed Pharmacother 131, 110663.

60. Vatin M, Bouvier S, Bellazi L, et al. (2014) Polymorphisms of human placental alkaline phosphatase are associated with in vitro fertilization success and recurrent pregnancy loss. Am J Pathol 184, 362-368.

61. Hirschmugl B, Crozier S, Matthews N, et al. (2018) Relation of placental alkaline phosphatase expression in human term placenta with maternal and offspring fat mass. Int J Obes 42, 1202-1210.

62. Koren S \& Fantus IG (2007) Inhibition of the protein tyrosine phosphatase PTP1B: potential therapy for obesity, insulin resistance and type-2 diabetes mellitus. Best Pract Res Clin Endocrinol Metab 21, 621-640.
63. Cunningham JJ (1998) Micronutrients as nutriceutical interventions in diabetes mellitus. J Am Coll Nutr 17, 7-10.

64. Kocaturk PA, Kavas GO, Erdeve O, et al. (2004) Superoxide dismutase activity and zinc and copper concentrations in growth retardation. Biol Trace Elem Res 102, 51-59.

65. Kocaturk PA, Siklar Z, Kavas GO, et al. (2002) Zinc treatment affects superoxide dismutase activity in growth retardation. Biol Trace Elem Res 90, 39-46.

66. Baltaci AK, Mogulkoc R \& Baltaci SB (2019) Review: the role of zinc in the endocrine system. Pak J Pharm Sci 32, 231-239.

67. Keller SR (2003) The insulin-regulated aminopeptidase: a companion and regulator of GLUT4. Front Biosci 8, s410-s420.

68. Keller SR (2004) Role of the insulin-regulated aminopeptidase IRAP in insulin action and diabetes. Biol Pharm Bull 27, 761-764.

69. Ju W, Li X, Li Z, et al. (2017) The effect of selenium supplementation on coronary heart disease: a systematic review and meta-analysis of randomized controlled trials. J Trace Elem Med Biol 44, 8-16.

70. Langston W, Circu ML \& Aw TY (2008) Insulin stimulation of gamma-glutamylcysteine ligase catalytic subunit expression increases endothelial GSH during oxidative stress: influence of low glucose. Free Radic Biol Med 45, 1591-1599.

71. Yoshioka J (2015) Thioredoxin reductase 2 (Txnrd2) regulates mitochondrial integrity in the progression of age-related heart failure. J Am Heart Assoc 4, e002278.

72. Zachara BA (2018) Selenium in complicated pregnancy. A review. Adv Clin Chem 86, 157-178.

73. van Gucht ALM, Meima ME, Moran C, et al. (2017) Anemia in patients with resistance to thyroid hormone alpha: a role for thyroid hormone receptor alpha in human erythropoiesis. J Clin Endocrinol Metab 102, 3517-3525.

74. Ejima K, Nanri H, Toki N, et al. (1999) Localization of thioredoxin reductase and thioredoxin in normal human placenta and their protective effect against oxidative stress. Placenta 20, 95-101.

75. Ganapathy S \& Volpe SL (1999) Zinc, exercise, and thyroid hormone function. Crit Rev Food Sci Nutr 39, 369-390.

76. Arthur JR \& Beckett GJ (1999) Thyroid function. Br Med Bull 55, 658-668.

77. Panicker V, Saravanan P, Vaidya B, et al. (2009) Common variation in the $\mathrm{DIO} 2$ gene predicts baseline psychological well-being and response to combination thyroxine plus triiodothyronine therapy in hypothyroid patients. J Clin Endocrinol Metab 94, 1623-1629.

78. Salvatore D, Low SC, Berry M, et al. (1995) Type 3 lodothyronine deiodinase: cloning, in vitro expression, and functional analysis of the placental selenoenzyme. J Clin Invest 96, 2421-2430.

79. Gupta RK, Gangoliya SS \& Singh NK (2015) Reduction of phytic acid and enhancement of bioavailable micronutrients in food grains. J Food Sci Technol 52, 676-684.

80. Watkins PA, Moser AB, Toomer CB, et al. (2010) Identification of differences in human and great ape phytanic acid metabolism that could influence gene expression profiles and physiological functions. BMC Physiol 10, 19.

81. Gibson RS, Raboy V \& King JC (2018) Implications of phytate in plant-based foods for iron and zinc bioavailability, setting dietary requirements, and formulating programs and policies. Nutr Rev 76, 793-804.

82. McGee M, Bainbridge S \& Fontaine-Bisson B (2018) A crucial role for maternal dietary methyl donor intake in epigenetic programming and fetal growth outcomes. Nutr Rev 76, 469-478.

83. Topal G, Brunet A, Millanvoye E, et al. (2004) Homocysteine induces oxidative stress by uncoupling of $\mathrm{NO}$ synthase activity through reduction of tetrahydrobiopterin. Free Radic Biol Med 36, 1532-1541.

84. Obeid R, Awwad HM, Knell AI, et al. (2018) Glucose and fat tolerance tests induce differential responses in plasma choline metabolites in healthy subjects. Nutrients 10, 1209.

85. Azzini E, Ruggeri S \& Polito A (2020) Homocysteine: its possible emerging role in at-risk population groups. Int J Mol Sci 21, 1421. 
86. Kalhan SC (2016) One carbon metabolism in pregnancy: impact on maternal, fetal and neonatal health. Mol Cell Endocrinol 435, 48-60.

87. Vettore L, Westbrook RL \& Tennant DA (2020) New aspects of amino acid metabolism in cancer. Br J Cancer 122, 150-156.

88. Levin B (1971) Hereditary metabolic disorders of the urea cycle. Adv Clin Chem 14, 65-143.

89. Jones ME (1970) Regulation of pyrimidine and arginine biosynthesis in mammals. Adv Ensyme Regul 9, 19-49.

90. Nielsen TT, Stottrup NB, Lofgren B, et al. (2011) Metabolic fingerprint of ischaemic cardioprotection: importance of the malate-aspartate shuttle. Cardiovasc Res 91, 382-391.

91. Bjorndal B, Brattelid T, Strand E, et al. (2013) Fish oil and the pan-PPAR agonist tetradecylthioacetic acid affect the amino acid and carnitine metabolism in rats. PLOS ONE 8, e66926.

92. Paik WK \& Kim S (1971) Protein methylation. Science 174, 114-119.

93. Vaz FM \& Wanders RJ (2002) Carnitine biosynthesis in mammals. Biochem J 361, 417-429.

94. Zheng H, Gupta V, Patterson-Fortin J, et al. (2013) A BRISC-SHMT complex deubiquitinates IFNAR1 and regulates interferon responses. Cell Rep 5, 180-193.

95. Morscher RJ, Ducker GS, Li SH, et al. (2018) Mitochondrial translation requires folate-dependent tRNA methylation. Nature 554, 128-132.

96. Giardina G, Brunotti P, Fiascarelli A, et al. (2015) How pyridoxal 5'-phosphate differentially regulates human cytosolic and mitochondrial serine hydroxymethyltransferase oligomeric state FEBS J 282, 1225-1241.

97. Pacana T, Cazanave S, Verdianelli A, et al. (2015) Dysregulated hepatic methionine metabolism drives homocysteine elevation in diet-induced nonalcoholic fatty liver disease. PLOS ONE 10, e0136822.

98. Zeisel SH (2012) A brief history of choline. Ann Nutr Metab 61, 254-258.

99. Zeisel SH \& da Costa KA (2009) Choline: an essential nutrient for public health. Nutr Rev 67, 615-623.

100. Chandler TL \& White HM (2017) Choline and methionine differentially alter methyl carbon metabolism in bovine neonatal hepatocytes. PLOS ONE 12, e0171080.

101. Panchaud N, Peli-Gulli MP \& De Virgilio C (2013) Amino acid deprivation inhibits TORC1 through a GTPase-activating protein complex for the Rag family GTPase Gtr1. Sci Signal 6, ra42.

102. Shin HJ, Kim H, Oh S, et al. (2016) AMPK-SKP2-CARM1 signalling cascade in transcriptional regulation of autophagy. Nature 534, 553-557.

103. Henagan TM, Laeger T, Navard AM, et al. (2016) Hepatic autophagy contributes to the metabolic response to dietary protein restriction. Metabolism 65, 805-815.

104. Wang H, Wilson GJ, Zhou D, et al. (2015) Induction of autophagy through the activating transcription factor 4 (ATF4)-dependent amino acid response pathway in maternal skeletal muscle may function as the molecular memory in response to gestational protein restriction to alert offspring to maternal nutrition. BrJ Nutr 114, 519-532.

105. Strakovsky RS, Zhou D \& Pan YX (2010) A low-protein diet during gestation in rats activates the placental mammalian amino acid response pathway and programs the growth capacity of offspring. J Nutr 140, 2116-2120.

106. Navarro F, Ramirez-Sarmiento CA \& Guixe V (2013) Catalytic and regulatory roles of species involved in metal-nucleotide equilibriums in human pyridoxal kinase. Biometals 26, 805-812.

107. Chiba Y, Terada T, Kameya M, et al. (2012) Mechanism for folate-independent aldolase reaction catalyzed by serine hydroxymethyltransferase. FEBS J 279, 504-514.

108. Okabe Y, Sano T \& Nagata S (2009) Regulation of the innate immune response by threonine-phosphatase of eyes absent. Nature 460, 520-524.

109. Vera-Aviles M, Vantana E, Kardinasari E, et al. (2018) Protective role of histidine supplementation against oxidative stress damage in the management of anemia of chronic kidney disease. Pharmacenticals 11, 111.

110. Song BC, Joo NS, Aldini G, et al. (2014) Biological functions of histidine-dipeptides and metabolic syndrome. Nutr Res Pract 8, 3-10.

111. Pooya S, Blaise S, Moreno Garcia M, et al. (2012) Methyl donor deficiency impairs fatty acid oxidation through PGC-1alpha hypomethylation and decreased ER-alpha, ERR-alpha, and HNF-4alpha in the rat liver. J Hepatol 57, 344-351.

112. Longo N (2016) Primary carnitine deficiency and newborn screening for disorders of the carnitine cycle. Ann Nutr Metab 68, Suppl. 3, 5-9.

113. Nalecz KA \& Nalecz MJ (2016) [Carnitine - mitochondria and beyond]. Postepy Biochem 62, 85-93.

114. Banerjee R (1997) The Yin-Yang of cobalamin biochemistry. Chem Biol 4, 175-186.

115. Van Veldhoven PP, Mannaerts GP, Casteels M, et al. (1999) Hepatic alpha-oxidation of phytanic acid. A revised pathway. Adv Exp Med Biol 466, 273-281.

116. Casteels M, Foulon V, Mannaerts GP, et al. (2003) Alpha-oxidation of 3-methyl-substituted fatty acids and its thiamine dependence. Eur J Biochem 270, 1619-1627.

117. Miura Y (2013) The biological significance of omega-oxidation of fatty acids. Proc Jpn Acad Ser B Phys Biol Sci 89, 370-382.

118. Bonekamp NA, Volkl A, Fahimi HD, et al. (2009) Reactive oxygen species and peroxisomes: struggling for balance. Biofactors 35, 346-355.

119. Leiva A, Salsoso R, Saez T, et al. (2015) Cross-sectional and longitudinal lipid determination studies in pregnant women reveal an association between increased maternal LDL cholesterol concentrations and reduced human umbilical vein relaxation. Placenta 36, 895-902.

120. Mizuuchi M, Cindrova-Davies T, Olovsson M, et al. (2016) Placental endoplasmic reticulum stress negatively regulates transcription of placental growth factor via ATF4 and ATF6beta: implications for the pathophysiology of human pregnancy complications. J Pathol 238, 550-561.

121. Hamdy O, Porramatikul S \& Al-Ozairi E (2006) Metabolic obesity: the paradox between visceral and subcutaneous fat. Curr Diabetes Rev 2, 367-373.

122. Tchkonia T, Thomou T, Zhu Y, et al. (2013) Mechanisms and metabolic implications of regional differences among fat depots. Cell Metab 17, 644-656.

123. Kapoor N, Furler J, Paul TV, et al. (2019) Normal weight obesity: an underrecognized problem in individuals of South Asian Descent. Clin Ther 41, 1638-1642.

124. Kapoor N, Lotfaliany M, Sathish T, et al. (2020) Obesity indicators that best predict type 2 diabetes in an Indian population: insights from the Kerala Diabetes Prevention Program. J Nutr Sci 9, e15.

125. Kapoor N, Furler J, Paul TV, et al. (2019) The BMI-adiposity conundrum in South Asian populations: need for further research. $J$ Biosoc Sci 51, 619-621.

126. Anand SS, Tarnopolsky MA, Rashid S, et al. (2011) Adipocyte hypertrophy, fatty liver and metabolic risk factors in South Asians: the Molecular Study of Health and Risk in Ethnic Groups (mol-SHARE). PLoS ONE 6, e22112.

127. Despres JP \& Lemieux I (2006) Abdominal obesity and metabolic syndrome. Nature 444, 881-887.

128. Sivan E, Mazaki-Tovi S, Pariente C, et al. (2003) Adiponectin in human cord blood: relation to fetal birth weight and gender. $J$ Clin Endocrinol Metab 88, 5656-5660.

129. Chan TF, Yuan SS, Chen HS, et al. (2004) Correlations between umbilical and maternal serum adiponectin levels and neonatal birthweights. Acta Obstet Gynecol Scand 83, 165-169.

130. Kotani Y, Yokota I, Kitamura S, et al. (2004) Plasma adiponectin levels in newborns are higher than those in adults and positively correlated with birth weight. Clin Endocrinol 61, 418-423.

131. Tsai PJ, Yu CH, Hsu SP, et al. (2004) Cord plasma concentrations of adiponectin and leptin in healthy term neonates: positive correlation with birthweight and neonatal adiposity. Clin Endocrinol 61, 88-93. 
132. Lecke SB, Morsch DM \& Spritzer PM (2011) Leptin and adiponectin in the female life course. Braz.J Med Biol Res 44, 381-387.

133. Meher A, Sundrani D \& Joshi S (2015) Maternal nutrition influences angiogenesis in the placenta through peroxisome proliferator activated receptors: a novel hypothesis. Mol Reprod Dev 82, 726-734.

134. McCarthy FP, Drewlo S, English FA, et al. (2011) Evidence implicating peroxisome proliferator-activated receptor-gamma in the pathogenesis of preeclampsia. Hypertension 58, 882-887.

135. Viita H, Markkanen J, Eriksson E, et al. (2008) 15-lipoxygenase-1 prevents vascular endothelial growth factor A- and placental growth factor-induced angiogenic effects in rabbit skeletal muscles via reduction in growth factor mRNA levels, NO bioactivity, and downregulation of VEGF receptor 2 expression. Circ Res 102, 177-184.

136. Wang Z, Dou X, Yao T, et al. (2011) Homocysteine inhibits adipogenesis in 3T3-L1 preadipocytes. Exp Biol Med 236, 1379-1388.

137. Wang XC, Sun WT, Yu CM, et al. (2015) ER stress mediates homocysteine-induced endothelial dysfunction: modulation of IKCa and SKCa channels. Atherosclerosis 242, 191-198.

138. Houde AA, Guay SP, Desgagne V, et al. (2013) Adaptations of placental and cord blood ABCA1 DNA methylation profile to maternal metabolic status. Epigenetics 8, 1289-1302.

139. Lee MJ, Wu Y \& Fried SK (2013) Adipose tissue heterogeneity: implication of depot differences in adipose tissue for obesity complications. Mol Aspects Med 34, 1-11.

140. Cinti S (2018) Adipose organ development and remodeling. Compr Physiol 8, 1357-1431.

141. Giralt M \& Villarroya F (2013) White, brown, beige/brite: different adipose cells for different functions? Endocrinology 154, 2992-3000.
142. Sanchez-Gurmaches J, Hung CM, Sparks CA, et al. (2012) PTEN loss in the Myf5 lineage redistributes body fat and reveals subsets of white adipocytes that arise from Myf5 precursors. Cell Metab 16, 348-362.

143. Yates SC, Zafar A, Hubbard P, et al. (2013) Dysfunction of the mTOR pathway is a risk factor for Alzheimer's disease. Acta Neuropathol Commun 1, 3.

144. Ricoult SJ \& Manning BD (2013) The multifaceted role of mTORC1 in the control of lipid metabolism. EMBO Rep 14, 242-251.

145. Nakanishi H, Kurosaki M, Tsuchiya K, et al. (2015) L-carnitine reduces muscle cramps in patients with cirrhosis. Clin Gastroenterol Hepatol 13, 1540-1543.

146. Engel AG \& Angelini C (1973) Carnitine deficiency of human skeletal muscle with associated lipid storage myopathy: a new syndrome. Science 179, 899-902.

147. Oropeza-Moe M, Wisloff H \& Bernhoft A (2015) Selenium deficiency associated porcine and human cardiomyopathies. J Trace Elem Med Biol 31, 148-156.

148. Bhattacharya M (2015) A historical exploration of Indian diets and a possible link to insulin resistance syndrome. Appetite 95, 421-454.

149. Vecchio MG, Paramesh EC, Paramesh H et al. (2014) Types of food and nutrient intake in India: a literature review. Indian $J$ Pediatr 81, Suppl. 1, 17-22.

150. Gulati S, Misra A \& Sharma M (2017) Dietary fats and oils in India. Curr Diabetes Rev 13, 438-443.

151. Misra A, Singhal N, Sivakumar B, et al. (2011) Nutrition transition in India: secular trends in dietary intake and their relationship to diet-related non-communicable diseases. J Diabetes 3, 278-292. 